\title{
HISTOLOGIC ASSESSMENT OF PULP RESPONSE TO STRONTIUM RANELATE AND BISPHOSPHONATES WHEN COMPARED TO CALCIUM HYDROXIDE AS DIRECT PULP CAPPING MATERIALS. AN ANIMAL STUDY
}

\author{
Hend Mahmoud Abou El Nasr*, Hany Samy Sadek* and Mohamed Ayad Abd El Hamid**
}

\begin{abstract}
Aim: To compare strontium ranelate as a pulp capping agent to bisphosphonate and calcium hydroxide.

Materials and methods: The pulps of 36 premolars from 4 dogs were exposed and capped with one of 3 test materials, namely strontium ranelate, bisphosphonate, and calcium hydroxide. Half of the specimens underwent histologic evaluation at 6 weeks and the remaining half were assessed at 12 weeks. Each slide was scored from 1 to 3 according to hard tissue formation, inflammation, and odontoblastic differentiation. The $\mathrm{pH}$ of the 3 materials was also measured. Data were inspected using SPSS software and the recorded scores were statistically analyzed at 6 and 12 weeks.

Results: Calcium hydroxide was the only material that exhibited discontinuous dentin bridge at both evaluation periods. Strontium ranelate showed irregular hard tissue formation in few of the samples at 12 weeks; while bishphonate did not induce any hard tissue formation. All the materials exhibited severe to moderate inflammatory reaction at 6 weeks which subsided to mild inflammation at 12 weeks. Differentiation of odontoblasts was observed with all materials at both evaluation periods with no significant differences among them.
\end{abstract}

The average $\mathrm{pH}$ obtained for Dycal base was 9 , and 12 for the catalyst; for bisphosphonate the value was 6.8 ; and 8.6 for strontium ranelate.

Conclusions: Strontium ranelate was not as effective as calcium hydroxide as a pulp capping agent, while bisphosphonate failed to show any potential for hard tissue formation up to 12 weeks. However, all the test materials allowed healing of the pulp tissues.

KEY WORDS: Direct pulp capping, animal study, calcium hydroxide, bisphosphonate, strontium ranelate.

* Department of Endodontics, Faculty of Oral and Dental Medicine, Cairo University, Egypt

** Department of surgery, anesthesiology and radiology, Faculty of Veterinary Medicine, Cairo University, Egypt 


\section{INTRODUCTION}

Vital pulp therapy aims to treat reversible pulpal injury whenever the pulp is exposed by caries, trauma, or restorative procedures. The ultimate goals of treatment are to maintain pulp vitality and function, and completely restore dentin continuity beneath the injury (so-called hard tissue bridge formation) ${ }^{(1,2)}$. Optimal quality of the hard tissue bridge is a critical prerequisite for the long-term success of vital pulp therapy ${ }^{(2,3)}$. The reparative potential of the dentinpulp complex depends basically on the pulp status and the efficacy of treatment modalities, including the application of an effective capping material able to enhance the tissue healing potential, followed by adequate restoration to prevent chemical irritation and bacterial infection ${ }^{(4,5)}$.

Calcium hydroxide $(\mathrm{CaOH})$ has been considered the "gold standard" of direct pulp capping materials for several decades ${ }^{(6)}$. Its ability to enhance wound healing with reparative dentin formation has been well documented in experimental studies, and its favorable clinical effects are generally accepted (7). However, $\mathrm{CaOH}$ induces pulp surface inflammation and necrosis of the underlying pulp tissue ${ }^{(6-9)}$. Moreover, its physical limitations, namely high solubility; lack of adhesion; and degradation over time ${ }^{(8,10)}$, as well as the poor quality of the formed dentinal bridge containing multiple tunnel defects that cannot effectively protect the pulp ${ }^{(7,9)}$ and fails to provide hermetic seal ${ }^{(6-10)}$ has led scientists to seek new approaches.

Bisphosphonates (BP) are one of the most important antiresorptive agents used in the treatment of bone disorders, such as osteoporosis and Paget's disease ${ }^{(11,12)}$. In dentistry, bisphosphonates have been investigated as potential inhibitors of alveolar bone resorption in the treatment of periodontitis for over two decades ${ }^{(13-15)}$. Furthermore, surface application of bisphophonates reduced root resorption of replanted teeth in animal models ${ }^{(16)}$. However,
BP-related osteonecrosis of the jaw (BRONJ) is one of the complications of the administration of the $\operatorname{drug}^{(11)}$. Nonetheless, there is growing evidence that topical application does not cause osteonecrosis of the jaws ${ }^{(15)}$.

Strontium ranelate (Sr ranelate) is another material that has been used since 2006 to treat osteoporosis ${ }^{(17)}$. It has gained attention in osteoporosis therapy because it was found that $\mathrm{Sr}$ concentration in bone decreased rapidly after its withdrawal; a feature that distinguishes this agent from bisphosphonates that remain in bone forever ${ }^{(18)}$. Additionally, it offers two mechanisms of action; induction of osteoblastogenesis and suppression of osteoclastogenesis ${ }^{(19,20)}$. Hence, Sr ranelate could represent a desirable material indicated when hard tissue destruction occurs, but it was not investigated as a topical agent for this purpose. Therefore, the aim of the present study was to compare the efficacy of strontium ranelate to bisphosphonates and calcium hydroxide when used as a direct pulp capping agents.

\section{MATERIALS AND METHODS}

\section{Animal selection}

Thirty six premolars from four male dogs of undefined breed, aging 9 months and 1 year were prepared for the study.

The protocol of this study was approved by the Ethics Committee of The Faculty of Veterinary Medicine at Cairo University, Cairo, Egypt.

\section{Surgical procedure}

\section{Anaesthesia}

The dogs were sedated by intramuscular injection of Xylazine (Xylaject, Bayer, Munich, Germany) in a dose of $5 \mathrm{mg} / \mathrm{Kg}$ body weight, followed by intramuscular injection of $50 \mathrm{mg} / \mathrm{Kg}$ body weight $10 \%$ Ketamine $\mathrm{HCl}$ (Alfasan, Woerden, Netherlands). 


\section{Surgical steps}

After the dogs' anesthetization, 3 premolars in both maxillary and the right mandibular quadrants of each of the 4 dogs were disinfected with $10 \%$ Povidone-iodine (Betadine). Class V cavities were prepared on the buccal surface $2 \mathrm{~mm}$ above the gingival margin with a size 2 round bur at low speed under copious sterile water spray. Deepening of the pulpal floor for each cavity was performed until the appearance of the pulpal shadow, and then a sharp sterile probe was used to mechanically expose the pulp in order to produce a minimal amount of bleeding, which was controlled by flushing the cavities with saline and dried with sterile gauze.

\section{Classification}

The chart in figure 1 (Fig. 1) describes the classification of the samples. The 36 teeth were divided into 2 main groups $(n=18)$ according the evaluation period, then each group was categorized into 3 equal subgroups of 6 samples based on the test material as follows;

Group A: calcium hydroxide (Dycal Dentin, Dentsply Caulk Milford, DE, USA);

Group B: bisphosphonate (Egidronate, Egyphar, Egypt),

Group C: strontium ranelate $\left(\right.$ Protelos $^{\circledR}$, Les Laboratoires Servier, Gidy, France);
Finally, all the cavities were restored with Intermediate Restorative Material ${ }^{\circledR}$ (IRM; Caulk, Dentsply, USA).

\section{Placement of the materials}

Each material was mixed and loaded in the cavity at the time of operation, using a plastic instrument.

Strontium ranelate is presented as powder to be dissolved in a glass of water and taken orally. In order to obtain a paste, the powder was mixed with few drops of saline to a workable consistency, that was thick enough to be carried with a plastic instrument and loaded in the cavity.

Likewise, bisphosphonate is in the form of tablets that were crushed in a mortar and mixed with saline to the same consistency. As for Dycal, it was mixed as per the manufacturers' instructions. The base and the catalyst for Dycal were mixed in the ratio of 1:1 (v/v) and applied directly to the exposed pulps. All the cavities were restored with IRM applied with a flat plastic instrument; and the dogs were placed on a soft diet for 2 days postoperatively.

\section{Tissue specimens}

Two time points were designed for observing pulp responses. After 6 and 12 weeks, the dogs were sacrificed and jaw segments containing the teeth were removed together with the adjacent bone.

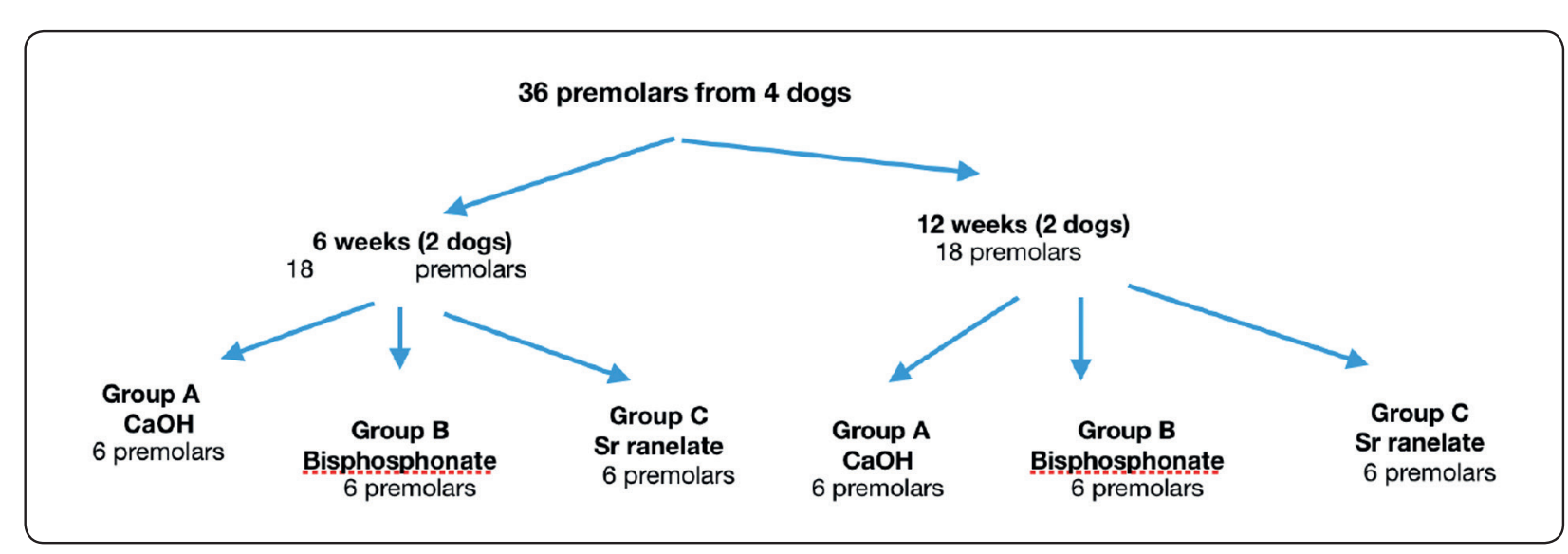

Fig. (1) A chart illustrating the classification of the samples according to the test materials and evaluation periods. 
After fixation in $10 \%$ formalin solution for 1 week, they were decalcified in 10\% EDTA and manually dehydrated in ascending grades of alcohol for 2 months. The specimens were then embedded in paraffin and sectioned bucco-lingually (in a sagittal orientation) to an average thickness of 5-6 $\mu \mathrm{m}$ and stained with hematoxylin and eosin.

\section{Histological assessment}

Histologic sections were evaluated using light microscopy by 2 calibrated examiners, who were blinded to the material used in each sample. The sections were scored from 1 to 3 for calcific bridge formation, inflammation, and the presence of odontoblastic layer using criteria adapted from Long et al (21) and based on those of Asgary et al $(22,23)$. Score 1 was described as being the worst score and 3 the best one.

Table 1 describes the scoring system and the criteria used for histologic evaluation of the specimens.

\section{PH Measurements of the test materials}

The $\mathrm{pH}$ of all materials was measured using a digital $\mathrm{pH}$ meter which was calibrated with standard $\mathrm{pH}$ solutions of $\mathrm{pH} 4.6$ and 9. The test tip was washed with distilled water and dried with tissue paper to prevent any contamination between the tests. In order to measure the $\mathrm{pH}$ of the test materials, strontium ranelate was dissolved in distilled water to form a suspension, while bisphosphonate tablet was crushed and then dissolved in distilled water to form a suspension. Because Dycal is rapidly setting after mixture, the base and the catalyst were tested separately. An average of 3 readings was taken for one $\mathrm{pH}$ value.

\section{Statistical analysis}

The mean and standard deviation values were calculated for each group. Data were explored for normality using Kolmogorov-Smirnov and Shapiro-Wilk tests which showed non-parametric distribution.

The recorded scores for the 3 materials were analyzed at 6 and 12 weeks by Kruskal-Wallis test. Wilcoxon-signed rank test was used for pairwise comparison between the 2 evaluation periods, while Mann-Whitney was used for pairwise comparison within the same evaluation period. The significance level was set at 0.05 . Data were analyzed using SPSS software (SPSS version 20, Chicago, IL, USA)

\section{RESULTS}

\section{Microscopic examination:}

\section{Calcium hydroxide (Dycal):}

At 6 weeks, all of the samples showed discontinuous dentin bridge with an irregular pattern of dentinal tubules, and exhibited severe inflammation with dilated blood vessels in the pulp (Fig. 2a). At 12 weeks, $40 \%$ of the cases showed induced calcification near the cavity containing the material with complete bridge formation (Fig. 2b); while $60 \%$ of the cases still had incomplete dentin bridge with no statistical significant difference between the scores reported at both periods $(\mathrm{p}=0.157)$. Moreover, severe inflammation subsided to mild inflammation in $60 \%$ of the cases, and palisades of TABLE (1) Criteria used for the histologic analysis of the pulps treated with direct pulp capping

\begin{tabular}{|c|c|c|c|}
\hline Score & Calcific bridge & Inflammatory response & Odontoblastic layer \\
\hline 1 & No formation & Intense inflammatory cell infiltrate & No cells observed \\
\hline 2 & $\begin{array}{c}\text { Discontinuous } \\
\text { bridge }\end{array}$ & $\begin{array}{c}\text { Mild to moderate inflammatory cells infiltrate } \\
\text { near to exposed pulp or in the coronal pulp }\end{array}$ & Presence of odontoblasts \\
\hline 3 & $\begin{array}{c}\text { Continusous } \\
\text { bridge }\end{array}$ & No inflammation & $\begin{array}{c}\text { Regular palisade pattern of } \\
\text { cells }\end{array}$ \\
\hline
\end{tabular}


odontoblastic layer were observed in $40 \%$ of the samples, but those changes were of no statistical significance as evidenced by $\mathrm{p}$ values of $(\mathrm{p}=0.083)$ and $(\mathrm{p}=0.317)$ respectively.

\section{Bisphosphonates:}

Bisphosphonate-treated samples showed lack of calcific bridge formation up to 12 weeks, where the mean score was 1 at both evaluation periods with no statistical significant difference between them
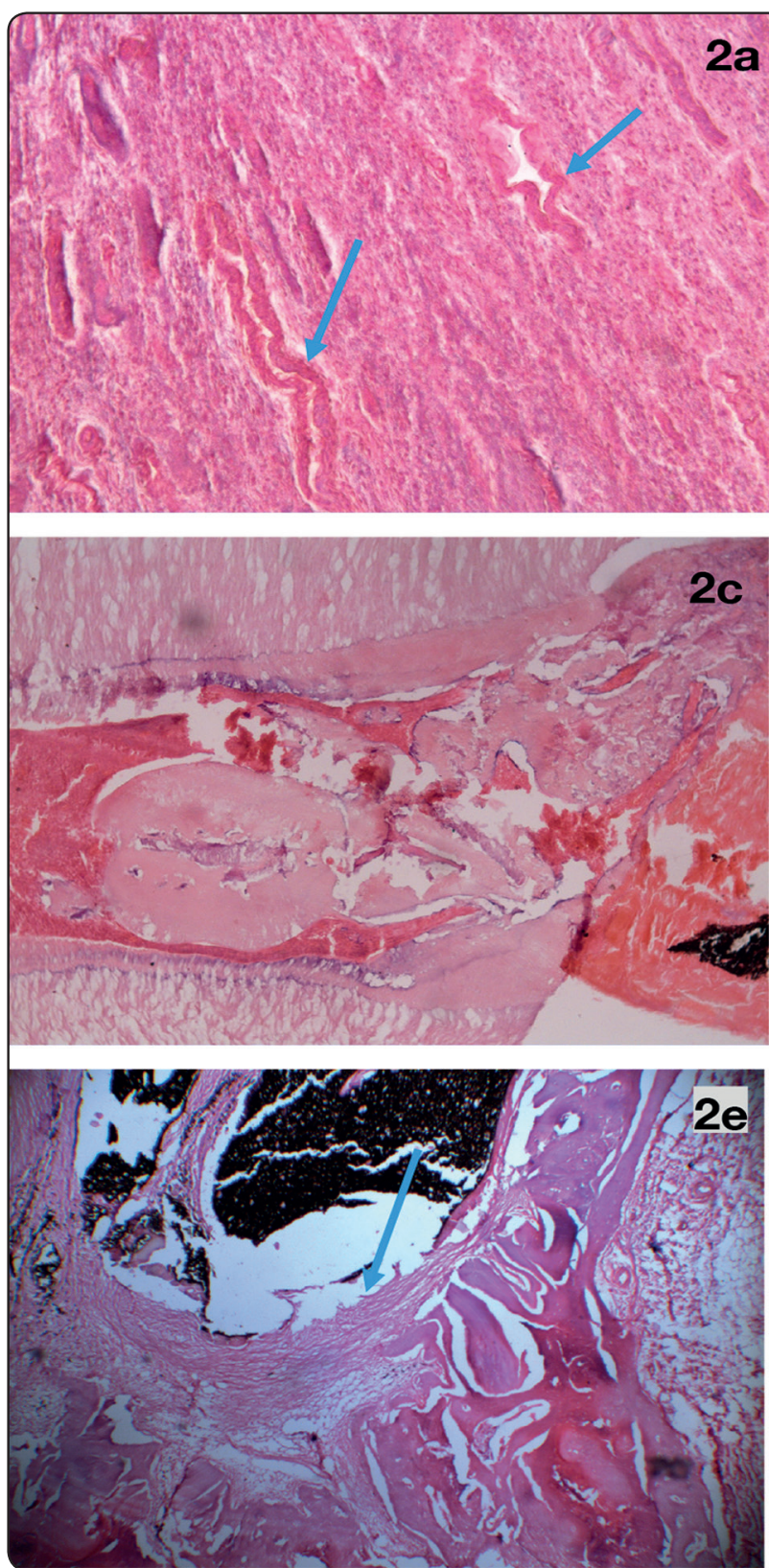

$(\mathrm{p}=1)$. Chronic inflammation with tortuous dilated blood vessels were evident at 6 weeks (Fig 2c); however, odontoblasts were observed. After 12 weeks, there was evidence of mild inflammation with wide dilated blood vessels in all of the samples. Pulp inflammation scored 1 at 6 weeks and significantly improved to score 3 at 12 weeks $(\mathrm{p}=0.025)$; while there was no statistically significant difference in odontoblastic layer mean scores between 6 weeks and 12 weeks $(p=1)$.
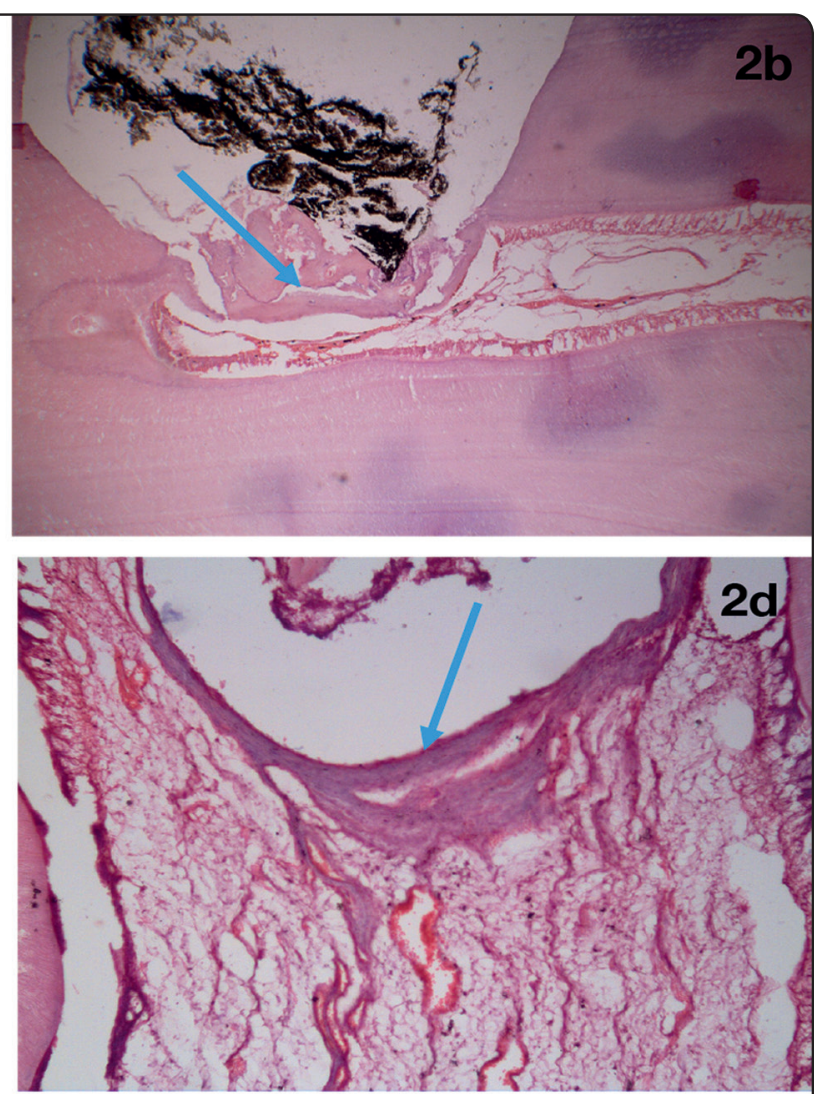

Fig. (2) Histologic assessment of the pulp tissue showing: (a) severe inflammation with tortuous blood vessels (arrows) in calcium hydroxide samples after 6 weeks 200x (b) discontinuous dentin bridge (arrow) at the interface with calcium hydroxide 40x (c) moderate inflammation in contact with bisphosphonate (d) strontium ranelate - treated samples with fibrosis (arrow) and chronic inflammation 200x (e) reparative dentin formation (arrow) in response to strontium ranelate after 12 weeks100x. 


\section{Strontium ranelate:}

There was no evidence of dentin bridge formation at 6 weeks despite the presence of odontoblasts, and the samples showed severe inflammatory reaction with numerous inflammatory cells (Fig. 2d). After 12 weeks, an irregular discontinuous dentinal bridge was observed in $20 \%$ of the cases, which was statistically non-significant $(\mathrm{p}=0.998)$. Moreover, non-significant organization of odontoblastic layer into palisades was observed $(\mathrm{p}=0.157)$. On the other hand, significant reduction of inflammation was evident in $60 \%$ of the samples ( $\mathrm{p}=0.038$ ) (Fig. 2e).

Differences in the tissue reactions to the 3 studied materials: (Tables 2 - 4)

\section{At 6 weeks:}

The pulpal tissues of teeth treated with $\mathrm{CaOH}$ exhibited significantly better quality of the formed dentin bridge than each of the strontium ranelate and bishposhonates $(\mathrm{p}=0.007)$, while no significant difference existed between strontium ranelate and bishposhonates $(\mathrm{p}=1)$.

Conversely, all materials had a mean score of 1 and exhibited severe inflammatory reaction with no significant differences among them $(\mathrm{p}=1)$. Likewise, $100 \%$ of all studied materials scored 2 for odontoblastic layer formation with no significant differences among them $(\mathrm{p}=1)$.

\section{At 12 weeks:}

The mean scoring for calcific bridge was 2.4 in samples capped with $\mathrm{CaOH}$ and was significantly better than the other tested materials $(\mathrm{p}=0.004)$. Despite the presence of a statistically significant difference between $\mathrm{CaOH}$ and each of bisphosphonate and strontium ranelate groups $(\mathrm{p}=0.005)$ and $(\mathrm{p}=0.014)$ respectively, no statistically significant difference was found between bisphosphonate and strontium ranelate $(\mathrm{p}=0.317)$ where no hard tissue formation was observed except in few samples treated with $\mathrm{Sr}$ ranelate.
The inflammatory reaction subsided in all materials with no significant differences existed among them $(\mathrm{p}=0.270)$. Moreover, although samples treated with $\mathrm{Sr}$ ranelate showed palisades of odontoblasts lining the pulp, no statistical significance occurred among the 3 test materials $(p=0.141)$.

TABLE (2) Mean, standard deviation (SD) and comparison of calcific bridge formation of all test-ed capping materialsMean values with different small letters in the same column indicate statisti-cally significant difference.

\begin{tabular}{|c|c|c|c|c|c|}
\hline \multirow{2}{*}{ Variables } & \multicolumn{5}{|c|}{ Dentine bridge } \\
\cline { 2 - 5 } & \multicolumn{2}{|c|}{ 6 weeks } & \multicolumn{2}{|c|}{12 weeks } & \multirow{2}{*}{-value } \\
\cline { 2 - 5 } & Mean & SD & Mean & SD & \\
\hline CaOH & $2.00^{\mathrm{aA}}$ & 0.00 & $2.40^{\mathrm{aA}}$ & 0.55 & $0.157 \mathrm{~ns}$ \\
\hline $\begin{array}{c}\text { Bisphos- } \\
\text { phonate }\end{array}$ & $1.00^{\mathrm{bA}}$ & 0.00 & $1.00^{\mathrm{bA}}$ & 0.00 & $1 \mathrm{~ns}$ \\
\hline $\begin{array}{c}\text { Strontium } \\
\text { ranelate }\end{array}$ & $1.00^{\mathrm{bA}}$ & 0.00 & $1.20^{\mathrm{bA}}$ & 0.45 & $0.998 \mathrm{~ns}$ \\
\hline $\boldsymbol{p}$-value & \multicolumn{3}{|c|}{$\mathbf{0 . 0 0 7}^{*}$} & \multicolumn{6}{|c|}{$\mathbf{0 . 0 0 4}^{*}$} & \\
\hline
\end{tabular}

Mean values with different capital letters in the same row indicate statistically significant difference. *; significant $(p<0.05) \quad n s ;$ non-significant $(p>0.05)$

TABLE (3) Mean, standard deviation (SD) and comparison of pulp inflammation of all tested capping materials

\begin{tabular}{|c|c|c|c|c|c|}
\hline \multirow{2}{*}{ Materials } & \multicolumn{5}{|c|}{ Pulp inflammation } \\
\cline { 2 - 6 } & \multicolumn{2}{|c|}{6 weeks } & \multicolumn{2}{|c|}{$12^{2}$ weeks } & \multirow{2}{*}{ p-value } \\
\cline { 2 - 6 } & Mean & SD & Mean & SD & \\
\hline CaOH & $1.00^{\text {aA }}$ & 0.00 & $2.20^{\text {aA }}$ & 1.10 & $0.083 \mathrm{~ns}$ \\
\hline Bisphosphonate & $1.00^{\mathrm{aB}}$ & 0.00 & $3.00^{\mathrm{aA}}$ & 0.00 & $0.025^{*}$ \\
\hline Strontium ranelate & $1.00^{\mathrm{aB}}$ & 0.00 & $2.60^{\mathrm{aA}}$ & 0.55 & $0.038^{*}$ \\
\hline p-value & \multicolumn{3}{|c|}{$1 \mathrm{~ns}$} & \multicolumn{5}{|c|}{$0.270 \mathrm{~ns}$} & \\
\hline
\end{tabular}

Mean values with different small letters in the same column indicate statistically significant difference. Mean values with different capital letters in the same row indicate statistically significant difference. *; significant $(p<0.05) \quad n s ;$ non-significant $(p>0.05)$ 
TABLE (4) Mean, standard deviation (SD) values and comparison of odontoblastic layer in all tested capping materials

\begin{tabular}{|c|c|c|c|c|c|}
\hline \multirow{3}{*}{ Materials } & \multicolumn{5}{|c|}{ Odontoblastic layer } \\
\hline & \multicolumn{2}{|c|}{6 weeks } & \multicolumn{2}{|c|}{12 weeks } & \multirow{2}{*}{$\mathrm{p}$-value } \\
\hline & Mean & $\mathrm{SD}$ & Mean & SD & \\
\hline $\mathrm{CaOH}$ & $2.00^{\mathrm{aA}}$ & 0.00 & $2.40^{\mathrm{aA}}$ & 0.55 & $0.317 \mathrm{~ns}$ \\
\hline Bisphosphonate & $2.00^{\mathrm{aA}}$ & 0.00 & $2.00^{\mathrm{aA}}$ & 0.00 & $1 \mathrm{~ns}$ \\
\hline $\begin{array}{l}\text { Strontium } \\
\text { ranelate }\end{array}$ & $2.00^{\mathrm{aA}}$ & 0.00 & $2.60^{\mathrm{aA}}$ & 0.55 & $0.157 \mathrm{~ns}$ \\
\hline p-value & \multicolumn{2}{|c|}{$1 \mathrm{~ns}$} & \multicolumn{2}{|c|}{$0.141 \mathrm{~ns}$} & \\
\hline
\end{tabular}

Mean values with different small letters in the same column indicate statistically significant difference. Mean values with different capital letters in the same row indicate statistically significant difference. *; significant $(p<0.05) n s ;$ non-significant $(p>0.05)$

\section{PH Measurements}

The average $\mathrm{pH}$ obtained for Dycal base was 9 and for catalyst was 12 ; for bisphosphonate 6.8 ; and strontium ranelate 8.6.

\section{DISCUSSION}

The current study aimed to investigate $\mathrm{Sr}$ ranelate as a pulp capping agent and compare it to bisphosphonate as well as the gold standard $\mathrm{CaOH}$.

The effects of the materials were observed by preparing mechanical exposures on vital, intact dogs' teeth with healthy pulp tissues.

In order to attribute the differences in pulpal response to the test materials only, the 3 test materials were distributed among the 3 quadrants of the same dog in all dogs. Moreover, all teeth were treated with a rigorous protocol for the pulp capping procedures, where control of bleeding was performed using sterile saline to avoid the use of $\mathrm{NaOCl}$ which has high $\mathrm{pH}$; and may extract growth factors from the walls of dentine and affect the results ${ }^{(24)}$. A negative control group with no pulp capping material was not added because the presence of an appropriate material seems of critical importance in pulp capping experiments ${ }^{(25,26)}$.
The criteria used in this study (reparative dentin formation, inflammation, and pulp tissue organization) are thought to be characteristics of the healing exposed pulp tissue, and can be considered prognostic indicators for the success of pulp capping (24-26).

The formation of a hard tissue bridge is desirable as a barrier against coronal microleakage and bacterial invasion (26) and can be interpreted as a sign of healing and a positive reaction to stimulation ${ }^{(22,23)}$.

The results of this study showed that $\mathrm{CaOH}$ produced a discontinuous dentin bridge at 6 weeks up to 12 weeks, with few samples demonstrating a continuous calcific barrier. This is in line with previous studies investigating $\mathrm{CaOH}$ at the same periods whether on animal ${ }^{(22)}$ or human subjects ${ }^{(24,25,27)}$.

The mineralizing action of $\mathrm{CaOH}$ is directly influenced by its high $\mathrm{pH}$, as it provides an alkaline environment, which encourages repair and active calcification. In the current study, Dycal was used for comparison instead of pure $\mathrm{CaOH}$ because the very high $\mathrm{pH}$ of $\mathrm{CaOH}$ creates superficial obliteration zones and coagulation necrosis where reparative dentine ultimately begins to form in deeper zones; while Dycal, with its lower $\mathrm{pH}$, may avoid major tissue damage and stimulate reparative dentine more directly ${ }^{(22,24,28)}$. The alkaline $\mathrm{pH}$ could also activate alkaline phosphatase that play an important role in hard tissue formation ${ }^{(29)}$. The $\mathrm{pH}$ necessary for the activation of this enzyme varies from 8.6 to $10.3^{(29)}$. The $\mathrm{pH}$ for Dycal was previously reported to be approximately $10.5^{(30)}$, which was confirmed in the present study. While no information existed regarding those of the remaining materials used in this study; and that was needed to be able to interpret the results in light of the $\mathrm{pH}$ findings. Hence, the $\mathrm{pH}$ of the 3 materials were assessed and the results showed that $\mathrm{Sr}$ ranelate had an alkaline $\mathrm{pH}$ but lower than that of Dycal. This could produce fewer available hydroxyl and calcium ions on the material's surface; and eventually reduces or slows the precipitation of hydroxyapatite and 
overall healing ${ }^{(29)}$. Indeed, an irregular dentin bridge was formed at 12 weeks in few of the samples capped with $\mathrm{Sr}$ ranelate; which was consistent with a recent study reporting mineralized tissue formation after application of Sr ranelate to exposed pulps in rats' molars ${ }^{(19)}$, and endorses its ability to increase alkaline phosphatase activity ${ }^{(20)}$. On the other hand, the $\mathrm{pH}$ value for bisphosphonates was nearly neutral (6.8); thus, it was not expected to induce any state of alkalinity at the exposure site. In fact, none of the bisphosphonate- treated samples showed evidence of hard tissue deposition at both periods.

To the authors' knowledge, bisphosphonates were not previously tested as pulp capping agents; although earlier in vitro findings showed that alendronate was able to accelerate apical hard tissue growth during apexification ${ }^{(31)}$, and deposition of reparative dentin was reported along root canal walls of pulpotomized rat molars; but still there was no evidence of dentin matrix formation at the exposure site in addition to the presence of disorganized pulp tissue ${ }^{(32)}$. Bisphosphonate is known to act by inhibiting osteoclasts ${ }^{(12)}$. They have been widely experimented in root resorption conditions where topical application reduced resorption ${ }^{(16)}$; but little evidence exists as to its effects on odontoblasts. This is where lies the major advantage and substantial distinction with $\mathrm{Sr}$ ranelate where osteoblastic and odontoblastic differentiation were demonstrated ${ }^{(19,33)}$ and its anabolic effect has been established in addition to its anti catabolic effect on human hard tissues ${ }^{(33,34)}$.

In histologic studies, reparative dentin is commonly seen as a final zone of dentin-like matrix in association with a zone of osteotypic hard tissue (osteodentin/fibrodentin) followed by a layer of odontoblastlike cells ${ }^{(27)}$. Thus, the therapeutic validity of a given pulp capping material might be evaluated on the basis of its ability to stimulate directly odontoblastlike cell differentiation (2). Most of the samples in the present study exhibited odontoblast- like cells under the formed matrix, whereas few of these cells were in a palisade pattern, corroborating earlier observations ${ }^{(22,23)}$.

Formation of hard tissue at the interface of the pulp and the foreign material is nonetheless a controversial issue, because dentinal bridge presence does not necessarily prove a healthy status of the pulp or establishment of an optimum seal, but it can be interpreted merely as a reaction to irritation ${ }^{(22,23)}$. That's why inflammation intensity and histological state of the pulp tissue were assessed.

Pulp tissue in the present study displayed intense to moderate inflammation with all the test materials at 6 weeks, then significant improvement occurred by 12 weeks, coinciding with previous findings ${ }^{(22)}$. The presence of acute and chronic inflammation of the pulp until the longest observation period (12 weeks) after capping was a common feature in Dycal specimens; which was similar to results obtained by Parolia et al. ${ }^{(24)}$ and Nair et al. ${ }^{(27)}$.

Short term inflammation is considered by many to be caused by traumatic injury during cavity preparation ${ }^{(25)}$; and gradual healing over the study period may be a sign of biological acceptance of the materials used in this investigation.

Direct pulp capping is an attempt to maintain the vitality of an exposed dental pulp. An appropriate material is one of the main factors affecting favorable outcome of this procedure. However, information regarding the physical properties of strontium ranelate and bisphosphonate is scarce, since this is not the intent of their use, or the form supplied by their respective manufacturers. The current investigation showed that strontium ranelate displayed weaker ability to induce hard tissue formation than calcium hydroxide; while bisphosphonate failed to induce hard tissue formation up to 12 weeks. However, signs of healing and subsidence of inflammation were observed in the pulp tissue with all the materials under investigation. 


\section{CONCLUSION}

Under the conditions of this study, it was concluded that strontium ranelate is not as effective as calcium hydroxide as a pulp capping agent; but it is superior to bisphosphonate which did not induce hard tissue deposition up to 12 weeks. On the other hand, all materials displayed signs of healing where pulp tissue inflammation subsided from severe to mild by the end of the experiment, and odontoblastic cells were observed at both evaluation periods.

\section{Conflict of interest and source of funding:}

The authors deny any conflict of interest.

\section{ACKNOWLEDGEMENT}

We affirm that we have no financial affiliation or involvement with any commercial organization with direct financial interest in the subject or materials discussed in this manuscript, nor have any such arrangements existed in the past three years. The authors deny any conflicts of interest.

The authors wish to thank Dr. Nermine Raouf and Dr. Safa Fathy, associate professors of Oral Pathology at the Faculty of Oral and Dental Medicine, Cairo University, for their help with the histologic assessment part of this study. We would like also to extend our appreciation to Dr. Karim Fawzy, associate professor of Periodontology at the Faculty of Oral and Dental Medicine, Cairo University, for his kind assistance with the statistical analysis.

\section{REFERENCES}

1. Bogen, G., Kuttner, and S. Chandler, N. (2015). Vital pulp therapy. In: Cohen's pathways of the pulp. $11^{\text {th }}$ ed. Elsevier.

2. Tziafa, C., Koliniotou-Koumpia, E., Papadimitriou, S., Tziafas, D. (2014). Dentinogenic responses after direct pulp capping of miniature swine teeth with Biodentine. J Endod, 40 (12), pp. 1967-1971.

3. Bergenholtz, G. Advances since the paper by Zander and Glass (1949) on the pursuit of healing methods for pulpal exposures: historical perspectives. Oral Surg Oral Med Oral Pathol Oral Radiol Endod, 100 (suppl 2), pp.102-108.

1. Cho, SY., Seo, DG., Lee, SJ., Lee, J., Lee, SJ., Jung, IY. (2013). Prognostic factors for clinical outcomes according to time after direct pulp capping. J Endod, 39 (3), pp.327-331

2. Mente, J., Geletneky, B., Ohle, M., et al (2010). Mineral trioxide aggregate or calcium hydroxide direct pulp capping: an analysis of the clinical treatment outcome. J Endod, 36 (5), pp.806-813.

3. Li, Z., Cao, L., Fan, M., Xu, Q. (2015). Direct pulp capping with calcium hydroxide or mineral trioxide aggregate: A meta-analysis. J Endod, 41 (9), pp. 1412-1417.

4. Cox, CF., Tarim, B., Kopel, H., et al (2001). Technique sensitivity: biological factors contributing to clinical success with various restorative materials. Adv Dent Res, 15 (1), pp. 85-90.

5. Hilton, TJ. (2009). Keys to clinical success with pulp capping: a review of the literature. Oper Dent, 34 (5), pp. 615-625.

6. Kitasako, Y., Ikeda, M., Tagami, J. (2008) Pulpal responses to bacterial contamination following dentin bridging beneath hard-setting calcium hydroxide and self-etching adhesive resin system. Dent Traumatol, 24 (2), pp. 201-206.

7. Cox, CF., Subay, RK., Ostro, E., et al (1996). Tunnel defects in dentin bridges: their formation following direct pulp capping. Oper Dent, 21 (1), pp. 4-11.

8. Moinzadeh, AT., Shemesh, H., Neirynck, NA., Aubert, C., Wesselink, PR. (2013). Bisphosphonates and their clinical implications in endodontic therapy. Int Endod J, 46 (5), pp. 391-398.

9. Martins, CA., Leyhausen, G., Volk, J., Geurtsen, W. (2015). Effects of alendronate on osteoclast formation and activity In vitro. J Endod, 41 (1), pp. 45-49

10. Pradeep, AR., Kumari, M., Rao, NS., Naik, SB. (2013). $1 \%$ Alendronate gel as local drug delivery in the treatment of class II furcation defects: A randomized controlled clinical trial. J Periodontol, 84 (3). pp. 307-315.

4. Sharma, A., Pradeep, AR. (2012). Clinical efficacy of $1 \%$ alendronate gel as a local drug delivery system in the treatment of chronic periodontitis: A randomized, controlled clinical trial. J Periodontol, 83 (1). pp. 11-18.

5. Shah, NP., Nayee, S., Pazianas, M., Sproat, C. (2017). Beyond $\mathrm{ONJ}$ - A review of the potential uses of bisphosphonates in dentistry. Br Dent J, 222 (9). pp. 727-730 
11. Najeeb, S., Siddiqui, F., Khurshid, Z., Zohaib, S., Zafar, MS., Ansari, SA. (2017). Effect of bisphosphonates on root resorption after tooth replantation - a systematic review. Dent Traumatol, 33 (2), pp. 77-83

12. Romieu, G., Garric, X., Munier, S., Vert, M., Boudeville, P. (2010). Calcium-strontium mixed phosphate as novel injectable and radio-opaque hydraulic cement. Acta Biomater, 6 (8), pp. 3208-3215.

13. Nielsen, SP. (2004). The biological role of strontium. Bone, 35 (3), pp.583-588.

14. Bakhit, A., Kawashima, N., Hashimoto, K., Noda, S., Nara, K., Kuramoto, M., Tazawa, K., Okiji, T. (2018). Strontium ranelate promotes odonto-/osteogenic differentiation/mineralization of dental papillae cells in vitro and mineralized tissue formation of the dental pulp in vivo. Sci Rep, 15:8(1), pp. 9224.

15. Marie, PJ. (2006). Strontium ranelate: A physiological approach for optimizing bone formation and resorption. Bone, 38 (2 Suppl 1), pp. S10-14.

16. Long, Y., Liu, S., Zhu, L., Liang, Q., Chen, X., Dong, Y. (2017). Evaluation of pulp response to novel bioactive glass pulp capping materials. J Endod, 43 (10), pp. 16471650 .

17. Asgary, S., Eghbal, MJ., Parirokh, M., Ghanavati, F., Rahimi, H. (2008). A comparative study of histologic response to different pulp capping materials and a novel endodontic cement. Oral Surg Oral Med Oral Pathol Oral Radiol Endod, 106 (4), pp. 609-614

18. Zarrabi, MH., Javidi, M., Jafarian, AH., Joushan, B. (2010). Histologic assessment of human pulp response to capping with mineral trioxide aggregate and a novel endodontic cement. J Endod, 36 (11), pp. 1778 - 1781

19. Parolia, A., Kundabala M, Rao NN, Acharya SR, Agrawal P, Mohan M, Thomas M. (2010). A comparative histological analysis of human pulp following direct pulp capping with Propolis, mineral trioxide aggregate and Dycal. Aust Dent J, 55 (1), pp. 59-64
20. Lu, Y., Liu, T., Li, H., Pi, G. (2008). Histological evaluation of direct pulp capping with a self-etching adhesive and calcium hydroxide on human pulp tissue. Int Endod J, 41 (8), pp. 643-650

21. Woodmansey, KF., Kohout, GD., Primus, CM., Schneiderman, E., Opperman, LA. (2015). Histologic assessment of Quick-Set and mineral trioxide aggregate pulpotomies in a canine model. J Endod, 41 (10), pp. 1626-1630.

22. Nair, PNR., Duncan, HF., Pitt Ford, TR., Luder, HU. (2008). Histological, ultrastructural and quantitative investigations on the response of healthy human pulps to experimental capping with mineral trioxide aggregate: a randomized controlled trial. Int Endod J, 41 (2), pp. 128-150.

23. Stanley, HR., Lundy, T. (1972). Dycal therapy for pulp exposures. Oral Surg Oral Med Oral Pathol, 34 (5), pp. 818-827

24. Mohammadi, Z., Dummer, PMH. (2011). Properties and applications of calcium hydroxide in endodontics and dental traumatology. Int Endod J, 44 (8), pp. 697-730.

25. Ida, K., Maseki,T., Yamasaki, M., Hirano, S., Nakamura, H. (1989). The $\mathrm{pH}$ values of pulp-capping agents. J Endod, 15 (8), pp. 365-368

26. Sommercorn, LM., Di Fiore, PM., Dixit, SN., Koerber, A., Lingen, MW., Veis, A. (2000). Effect of alendronate on immature human dental root explants. J Endod, 26 (3), pp. $133-137$

27. Cengiz, SB., Batirbaygil, Y., Onur, MA., Atilla, P., Asan, E., Altay, N., Cehreli, ZC. (2005). Histological comparison of alendronate, calcium hydroxide and formocresol in amputated rat molar. Dental Traumatology, 21 (5), pp. 281-288

28. Brennan, TC., Rybchyn, MS., Green, W., Atwa, S., Conigrave, AD., Mason, RS. (2009). Osteoblasts play key roles in the mechanisms of action of strontium ranelate. British Journal of Pharmacology, 157 (7). pp. 1291-1300

29. Reginster, JY. (2002). Strontium ranelate in osteoporosis. Curr Pharm Des, 8 (21), pp.1907-1916. 